\title{
Les écritures secrètes, études réunies et présentées par Michel Briand, Colette Camelin et Liliane Louvel
}

\section{Gabriella Bosco}

\author{
(2) OpenEdition \\ Journals \\ Edizione digitale \\ URL: http://journals.openedition.org/studifrancesi/7084 \\ DOI: $10.4000 /$ studifrancesi.7084 \\ ISSN: 2421-5856

\section{Editore} \\ Rosenberg \& Sellier
}

\section{Edizione cartacea}

Data di pubblicazione: 1 septembre 2010

Paginazione: 423-424

ISSN: 0039-2944

\section{Notizia bibliografica digitale}

Gabriella Bosco, «Les écritures secrètes, études réunies et présentées par Michel Briand, Colette Camelin et Liliane Louvel», Studi Francesi [Online], 161 (LIV | II) | 2010, online dal 30 novembre 2015 consultato il 07 janvier 2021. URL: http://journals.openedition.org/studifrancesi/7084 ; DOI: https:// doi.org/ERREUR PDO dans /localdata/www-bin/Core/Core/Db/Db.class.php L.34 : SQLSTATE[HY000] [2006] MySQL server has gone away

Questo documento è stato generato automaticamente il 7 janvier 2021. 


\title{
Les écritures secrètes, études réunies et présentées par Michel Briand, Colette Camelin et Liliane Louvel
}

\author{
Gabriella Bosco
}

\section{NOTIZIA}

AA.VV., Les écritures secrètes, études réunies et présentées par Michel BRIAND, Colette CAMELIN et Liliane LOUVEL, «La Licorne», Presses Universitaires de Rennes, 87, 2009, pp. 315.

1 Il volume raccoglie gli atti del convegno tenutosi alla Maison des Sciences de l'Homme et de la Société (Université de Poitiers) dal 21 al 23 settembre del 2007, il cui obiettivo era quello di classificare le diverse forme di scritture segrete-codici, scritture clandestine, manoscritti dissimulati, samizdat, pseudonimi, romanzi à clé, testi ermetici - per individuarne le caratteristiche specifiche.

2 Un oggetto di studio definito dalla segretezza comporta tre ordini di interrogativi: che tipo di codificazione la scrittura mette in atto (con la conseguente decodificazione); che ruolo hanno rispettivamente autore e destinatario della scrittura; e di che natura è il segreto.

3 L'introduzione, a firma dei curatori, illustra la varietà delle problematiche affrontate, $\mathrm{e}$ l'ampiezza dell'arco cronologico come dell'orizzonte spaziale presi in considerazione (Des écritures cryptées au travail secret de la littérature, pp. 7-20).

4 Gli interventi sono poi organizzati in quattro sezioni. La prima, «En guise d'ouverture», introduce la segretezza intesa come elemento strutturale dell'atto di scrittura tramite l'esempio del passaggio dall'infanzia silenziosa alla narrazione finzionale (Gisèle BIENNE, Être à soi-même un secret, pp. 23-28), e poi attraverso la voce di un'autrice, Fanny HowE, che presenta il proprio romanzo The Deep North, edito negli Stati Uniti nel 1988 e tradotto da Mercure de France nel 1997, che quel passaggio mette in atto (Hidden faces, 
pp. 29-32), cui fa seguito una lettura critica dello stesso romanzo da parte di Bénédicte CHORIER-FRYD (Secret du retournement dans "Nord profond" de Fanny Howe, pp. 33-38).

5 La seconda sezione s'intitola «Cryptages» e passa in rassegna varie forme di scrittura criptata in testi molto lontani tra loro: da quelli omerici, dove la lingua segreta è associata a una situazione di conflitto (Sylvie PERCEAU, La langue secrète dans l'épopée homérique, pp. 41-60), alla corrispondenza clandestina di Marie-Antoinette (Claude BENOIT, L'écriture secrète de Marie-Antoinette, pp. 61-72), all'opera di Oscar Wilde, inventore di nomi segreti per provocazione (Emmanuel VERDANAKIS, «Les noms comptent plus que tout!!: secret, provocation et constructions identitaires dans l'ouvre d'Oscar Wilde, pp. 73-86), a un esempio di scrittura segreta imposta dalla dittatura nazional-socialista (Arvi SEPP, «Témoigner jusqu'au bout»: les journaux intimes de Victor Klemperer comme éciture secrète sous le national-socialisme, pp. 87-104). Chiude la sezione un intervento consacrato a un autore contemporaneo che considera la scrittura come una forma di dissidenza contro l'assurdità imperdonabile del mondo e che di conseguenza cripta l'utopia (Simon SAINT-ONGE, Ce que crypter veut dire ou l'expression utopique chez Antoine Volodine, pp. 105-120).

6 La seconda parte del volume è dedicata alle «Ruses de l'art», ovvero alle scritture segrete nella pittura. Béatrice LAURENT studia Le renouveau de l'herméneutique médiévale dans l'iconographie préraphaélite (pp. 123-140); Isabelle HERSANT si occupa di artistiMagritte, Filliou, Weiner - che usano la parola a firma o commento delle loro opere o all'interno delle stesse lavorando su una sostituzione di senso, come risposta al venir meno storico del senso ("Ceci est un poème et demi». Phrase surréaliste, vers Fluxus, axiome conceptuel: quand les mots de la langue font l'art comme langage, pp. 141-152). Mentre all'opposto Anne uLLmo si occupa di Rikki Ducornet e dell'uso che egli fa, nella scrittura, del riferimento alla pittura barocca ("The Jade Cabinet" de Rikki Ducornet: la langue et son venin, pp. 153-162).

7 Segue la sezione intitolata «Poétique» che comprende studi in cui sono analizzati generi diversi di segretezza letteraria: dall'esoterismo in contesto simbolista (PaulAndré CLAUDEL, Le hiéroglyphe et le grimoire: conceptions ésotériques de l'écriture dans la poésie fin-de-siècle, ou les voies secrètes du symbolisme, pp. 165-181) al segreto inviolabile rappresentato da Orlando di Virginia Woolf (Nathalie PAVEC, Figurer le secret: une esthétique ludique du simulacre chez Virginia Woolf, pp. 183-196); dalla doppia vacanza di autore e lettore nella concezione poetica di Paul Celan (Frédéric MARTEAU, Paul Celan et l'évidente obscurité du poème, pp. 197-209) alla poesia di Jouffroy nella quale il soggetto si esibisce per meglio nascondersi come forma di resistenza alla società dello spettacolo (Dominique BIоT, La poésie d'Alain Jouffroy: élaboration rhétorique du secret, pp. 211-224). Conclude la sezione un articolo su un romanzo contemporaneo ma scritto alla maniera di Sterne e in cui i segreti sono molteplici - di famiglia, politici, diplomatici, dello scrittore (Véronique ALEXANDRE, Le statut des énigmes dans "What a carve up!" de Jonathan Coe, pp. 225-237).

8 La quarta e ultima sezione presenta e interroga alcune teorie. Denis BoIsSAU riflette da filosofo sullo statuto di colui, l'autore, che detiene il segreto, quest'ultimo considerato non come qualcosa ch'egli nasconde ma come ciò che gli garantisce la sua autorialità (Secret, c'est pas..., enfin je crois, pp. 241-256). Anne-Lise worms risale alla teoria letteraria dei neoplatonici per i quali la poesia, non inferiore alla filosofia, è il luogo del senso nascosto (Les énigmes d'Homère: à propos de la théorie littéraire des néoplatoniciens, pp. 
257-272). Florian PENNANECH si occupa di Roland Barthes e della Nouvelle critique con l'idea che egli ritardi il deciframento dell'opera posponendola alla sua analisi formale, ovvero che l'opera sia per lui il segreto e la chiave per risolverlo (Le sens caché de la forme, pp. 273-290). E Francesca MANZARI conclude con Derrida e la scrittura plurale che, come il sogno, non si esaurisce in un senso e si apre invece facendosi inesauribile (Écriture derridienne et langage des rêves: le secret, l'inconscient et la poésie, pp. 291- 304).

9 Il volume comporta anche alcune utili pagine conclusive che informano su attività e ricerche di ognuno degli autori. 